\title{
Evaluation of the Danish mussel fishery: suggestions for an ecosystem management approach
}

Received: 4 December 2000 / Revised: 23 April 2001 / Accepted: 10 December 2001 / Published online: 9 February 2002 (C) Springer-Verlag and AWI 2002

\begin{abstract}
In Limfjorden, Denmark, an extensive mussel fishery exploits the wild stocks of Mytilus edulis with annual landings of 80,000-100,000 t of mussels. During the last 10 years the impact of mussel dredging on the ecosystem has been studied, including the effect of resuspension of sediment and nutrients and the impoverishment of in- and epi-fauna assemblages. Furthermore, dredging changes the physical structure and complexity of the seabed which affects mussel growth and interactions among zoobenthic species. The blue mussel constitutes the dominant fraction of the zoobenthic suspension feeders, and is important for the transport of material and energy from the pelagic to benthic systems and the control of phytoplankton biomass. In order to evaluate the impact on clearance capacity of a reduction in mussel densities due to mussel dredging, mussel filtration activity measured in situ has been related to the mixing of the water column and the amount of near-bed phytoplankton. Fishery practice for mussel dredging in Limfjorden is discussed in relation to its known impact on the ecosystem and the ecological role of the mussels, and modifications towards an ecosystem management approach and a more sustainable fishery are suggested. The suggested modifications include: a fishery practice where the mussel beds are thinned out when the mussels have attained good quality, and a transplantation practice of mussels from areas with a high mortality to areas with a high growth rate. Both practices intensify the production in a certain area, leaving other areas open for alternative production or for permanent closure for the benefit of the benthic flora and fauna. In addition, other shellfish species represent interesting new resources for fishing or aquaculture. Habitat restoration, such as the relaying of mussel shells from the mussel industry, is another impor-
\end{abstract}

Communicated by H. Asmus and R. Asmus

P. Dolmer $(-)$ R.P. Frandsen

Danish Institute for Fisheries Research, Charlottenlund Castle, 2920 Charlottenlund, Denmark

e-mail: pdo@dfu.min.dk tant management tool that should be included in an ecosystem management approach of the mussel fishery.

Keywords Mytulis edulis · Mussels · Dredging · Ecosystem $\cdot$ Fishery practice

\section{Introduction}

The exploitation of marine resources in coastal and estuarine areas is often in conflict with conservation and recreational interests, and an increasing political pressure enforces the regulation towards a more sustainable exploitation of these ecosystems (e.g. the FAO code of conduct for sustainable fisheries). Ecosystem management is a concept that can steer management practices towards a politically and scientifically acceptable management of natural resources. Ecosystem management has been defined as "Ecosystem management integrates scientific knowledge of ecological relationships within a complex socio-political and values framework toward the general goal of protecting native ecosystem integrity over the long term" (Grumbine 1994). In order to manage the coastal fisheries in accordance with the ecosystem management approach, a good knowledge of the ecological structure and function of coastal zones, and in particular knowledge of the impact of the exploitation, must be available.

In Denmark, the wild stocks of blue mussel, Mytilus edulis, are exploited for commercial fishery in three different areas; in the Danish Wadden Sea (5,000-10,000 t year $\left.^{-1}\right)$, along the east coast of Jutland $\left(30,000 \mathrm{t}^{\text {year }}{ }^{-1}\right)$ and in Limfjorden (80,000-100,000 t year-1). During the last 10 years the Danish Institute for Fisheries Research has conducted a number of investigations in Limfjorden where 51 vessels are licensed to fish in a $893 \mathrm{~km}^{2}$ area. In order to analyse the impact of mussel dredging on the ecosystem, a number of studies on the population dynamic of the mussels and on dredging-induced changes have been conducted in Limfjorden. These studies include investigations on mussel growth and filtration 
(Dolmer 1998, 2000a, b), the impact of dredging on the mussel stock (Dolmer et al. 1999), resuspension of sediment and nutrients during mussel dredging (Riemann and Hoffmann 1991; Dyekjær et al. 1995), the impact on the benthic in- and epifauna (Hoffmann and Dolmer 2000; Dolmer et al. 2002), and the impact on the seabed (P. Dolmer, unpublished results). The aim of this paper is to review the investigations on mussel ecology and the impact studies on the mussel fishery in Limfjorden, and to suggest a way towards an ecosystem management and more sustainable exploitation.

\section{The fishery of mussels in Limfjorden}

Limfjorden is a $1,575 \mathrm{~km}^{2}$ sound open to the North Sea to the west and to Kattegat to the east. The tidal range is low $(\sim 0.2 \mathrm{~m})$ and the water circulation is forced by the predominantly eastern-directed wind. This low energy system is eutrophic, receiving nutrients from surrounding areas, and the primary production is high, locally exceeding $1,000 \mathrm{mg} \mathrm{C} \mathrm{m}^{-2} \mathrm{day}^{-1}$ in summer. The combination of a high algal biomass and a low mixing rate of the water column frequently induces extensive events of oxygen depletion and mass mortality of benthic animals, especially in the more enclosed parts of the area (Jørgensen 1980; Dolmer et al. 1999). The standing stock of mussels in areas open to mussel dredging (see below) is $600,000 \mathrm{t}$, with large annual variations. In areas with an efficient mixing of the water column and transport of food particles down to the zoobenthic suspension feeders the growth rate of mussels is as high as that observed in the Wadden Sea and the mussels grow from settlement to the minimum legal catch size of $4.5 \mathrm{~cm}$ in approximately 2.5 years (Dolmer 1998). The quality of the mussels, measured as the ratio between the cooked weight of the meat and the total weight of the mussel, ranges from approximately $10 \%$ to $30 \%$, with a mean value of $17.2 \%$ (Fig. 1).

Fishery for mussels is rather restrictive in Limfjorden. The vessels must be licensed, be below a maximum size, and fishing is banned at water depth more shallow than two or three metres in order to reduce fishery impact on benthic flora and fauna and in particular to protect the seagrass beds. Furthermore, several areas in the sound are permanently closed in order to protect unique habitats. The fishery for mussels is normally closed in December and January voluntarily and from the beginning of July to the end of August by law. In cases of low oxygen concentration the closing down of the fishery during the summer has been voluntarily prolonged in order to avoid further reduction in oxygen concentrations due to the suspension of oxygen-consuming substances during fishing. The fishery is regulated by quotas and each vessel is allowed to land $70 \mathrm{t}$ per week in Limfjorden. However, the annual landings have always been much lower than the total allowable catch.

Since the late 1970s the landings of mussels have increased from approximately $20,000 \mathrm{t} \mathrm{year}^{-1}$ to the pres-

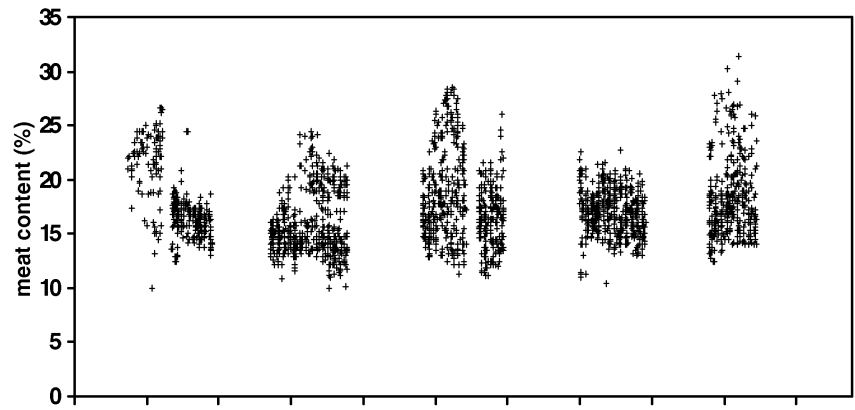

Jan-98 Apr-98 Jul-98 Oct-98 Dec-98 Mar-99 Jun-99 Sep-99 Dec-99 Mar-00 Jun-00

Fig. 1 Meat content of landed mussels in 1998-2000 measured as the cooked weight

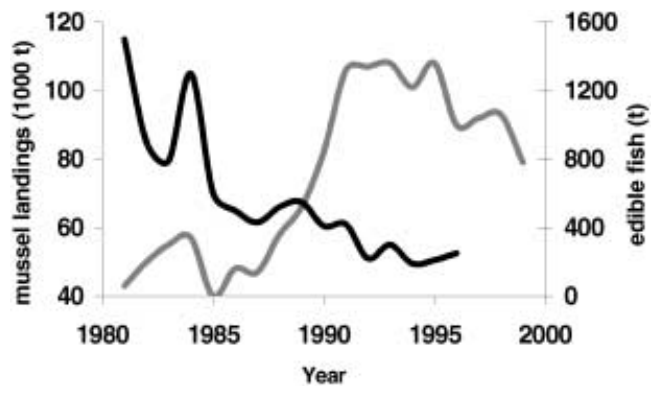

Fig. 2 Landings of blue mussels (grey line) and edible fish (black line) from Limfjorden from 1981 to 1999

ent landings and, at the same time, the fishery for edible benthic fish (eel, plaice, cod) has collapsed (Fig. 2). The obvious inverse correlation between mussel landings and fish populations has fostered a debate on the impact of mussel dredging on the ecosystem. An analysis of fishery data from 1993 to 1995 demonstrated that the fishery removed $15 \%$ of the mussel stock annually, ranging from 0 to $31 \%$ of the stocks in different areas (Dolmer et al. 1999). Furthermore, it was observed that the mussel biomass was inversely correlated with the intensity of fishing in years without oxygen depletion, whereas no correlation was observed in years with oxygen depletion. Since mussels are fished in approximately half the area of the sound and $15 \%$ of the stock open to fishery is exploited annually, a conservative estimate of the total area annually affected by mussel dredging is between 5\% and $10 \%$ of the sound. Estimates from the local environmental authorities show that $15-20 \%$ of the entire sound annually suffers from oxygen deficiency $\left(<2 \mathrm{mg} \mathrm{l}^{-1}\right)$, indicating that other anthropogenic and natural factors may also cause changes in the ecosystem. It is still an open question whether the ecosystem changes are driven by the impact of mussel dredging or by the massive eutrophication from the farmland in the area.

Limfjorden is different from most other European mussel-producing areas such as the Wadden Sea or the French bays, as there is no tide and the residence time of the water is extremely high (Dame and Prins 1998). Because of the low water exchange, the input of nutrients 
from the watershed is very important to the total amount of nutrients available for phytoplankton production and large amounts of the released nutrients are fixed in zoobenthic suspension-feeder biomass. Dolmer et al. (1999) estimated that the annual landing of 100,000 $t$ of mussels corresponded to a removal of nutrients equivalent to $7 \%$ of the annual nitrogen input and $40 \%$ of the annual phosphorus input from the watershed. Consequently, the mussel fishery significantly affects the nutrient cycles of the sound by removing mussels from the system. The mussel production can theoretically be used as a management tool in order to reduce the nutrient levels in the sound, as also suggested by Newell and Ott (2000). Haamer et al. (1999) introduced the agro-aqua concept for mussel farming. They suggest that a strategic farming of mussels can be used in order to remove excess nutrients from agro-production, and that these nutrients should be used for food production for human consumption.

\section{Review of the fishery's impact on the seabed}

Fishing with dredges and other types of towed bottom gear such as beam- and otter-trawls may change seabed topography and seabed composition (Hall 1990; Pranovi and Giovanardi 1994; Kaiser and Spencer 1996; Schwinghamer et al. 1998) and resuspend bottom sediment, oxygen-consuming substances and nutrients (Riemann and Hoffmann 1991; Dyekjær et al. 1995; Pilskaln et al. 1998). In field experiments Riemann and Hoffmann (1991) and Dyekjær et al. (1995) investigated the effect of seabed resuspension and the formation of sediment plumes from washing the mussels in the dredge at the sea surface prior to bringing the catch on board the fishing vessel. They showed that mussel dredging significantly increased the amount of suspended particulate matter for a few hours after dredging, and that the amount of oxygen decreased, whereas the amount of ammonia increased. Dyekjær et al. (1995) concluded that these impacts may have local effects on particle load and nutrient regimes, but that the overall effect in Limfjorden is insignificant compared with resuspension events during storms.

\section{Habitat complexity}

In a field study the amounts of shell debris and pebbles were measured in two areas where mussels had been dredged 4 months before the study (P. Dolmer, unpublished results). The amounts of these solid elements were compared to the amounts found in adjacent areas that are permanently closed. In both dredged areas the amount of shell debris was significantly smaller than in the closed areas (Fig. 3). Pebbles were only observed in one of the dredged areas and here the amount was significantly smaller than in the closed area. Also the number of $M y$ tilus spat was significantly lower in the dredged areas, indicating that mussel dredging reduces available substrate for settlement and/or postsettlement survival.
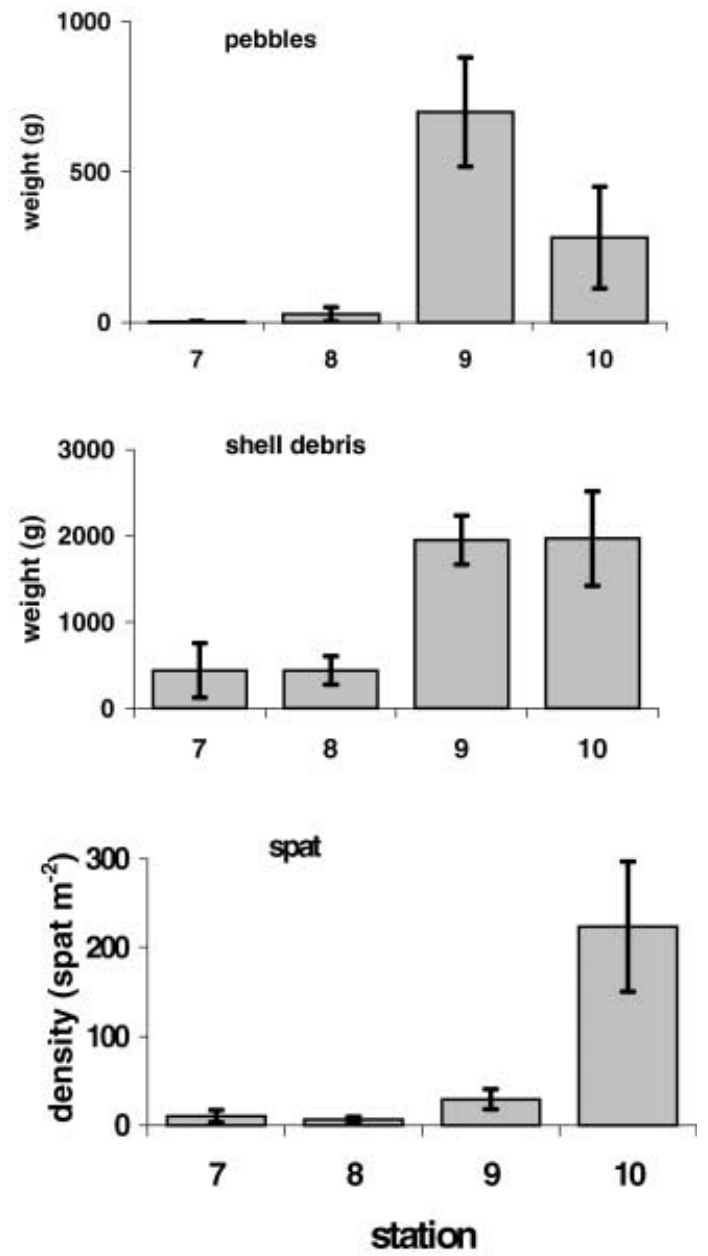

Fig. 3 Weight of pebbles and shell debris and density of juvenile mussels at two stations where mussels had been fished 4 months before sampling (stations 7 and 8) and two stations in two nearby permanently closed areas (stations 9 and 10). The rates are given as means $\pm 2 \mathrm{SE}$

In soft bottom habitats like Limfjorden solid elements, such as gravel and shell debris, and biogenic structures like mussel beds are of paramount importance to the benthic community. Larval settlement and recruitment of many invertebrates are strongly influenced by substrate structure (Botero and Atema 1982; Bourget et al. 1994; Jacobi and Langevin 1996; Lemire and Bourget 1996; Lapointe and Bourget 1999; Linnane et al. 2000). Compared with a smooth substrate such as mud or sand, the roughness of solid elements also increases turbulence above the seabed, which in turn will increase the amount of seston available to the benthic suspension feeders (Fréchette et al. 1989; Butman et al. 1994; Lenihan 1999). Moreover, the solid elements serve as attachment sites and increase substrate heterogeneity and complexity, providing refuges for prey and predators (Revelas 1982; Arnold 1984; Orth et al. 1984; Sponaugle and Lawton 1990; Lee and Kneib 1994; Hedvall et al. 1998). The altered composition of the seabed induced by dredging (P. Dolmer, unpublished results) thereby interferes 
with recruitment, growth and survival of the associated fauna.

Impact on settlement and recruitment

Experiments using artificial settling panels have shown that small-scale species distribution in early successional stages is significantly affected by both heterogeneity and complexity of the substrate (Bourget et al. 1994; Jacobi and Langevin 1996; Lemire and Bourget 1996; Lapointe and Bourget 1999), by orientation of the substrate (Glasby 2000) and by hydrodynamic processes (Butman et al. 1988; Lenihan 1999). Similar experiments with different types of naturally occurring substrate types have confirmed that several invertebrate larvae prefer complex substrata such as shell debris, gravel and macrophytes compared to sand and mud (Botero and Atema 1982; Hedvall et al. 1998; Linnane et al. 2000). Removal of solid structures by dredging may therefore impoverish the seabed and decrease local recruitment.

Impact on mussel growth

Near-bed mixing of the water column is determined by bottom roughness and flow speed. An increase in either factor will significantly increase the vertical transport of food to suspension-feeding benthic animals (Fréchette et al. 1989; Butman et al. 1994; Lenihan 1999). Several experiments conducted both in the field (Fréchette and Bourget 1985; Fréchette et al. 1989; Dolmer 2000a, b) and in flumes (Wildish and Kristmanson 1984; Butman et al. 1994) have shown that suspension-feeding animals, including blue mussels, are able to deplete seston from the near-bed layer. This indicates that at least some sections of a mussel bed may be food-limited and a change in near-bed mixing may therefore affect individual growth, especially in the downstream parts of mussel beds (Fréchette and Bourget 1985; Fréchette et al. 1989; Clausen and Riisgård 1996).

Since blue mussels may close their valves in response to tactile stimuli from shorecrabs and other larger motile species, the mere presence of these animals will influence the filtration activity and hence the growth of these zoobenthic filter feeders. The frequency of disturbance is related to the quality of the refuges that a substrate offers, and is therefore expected to directly affect growth, as well as survival.

\section{Predation}

The capacity of a habitat to mediate predation and thereby play a significant role in determining available prey abundance has long been appreciated (Orth et al. 1984). In laboratory experiments, Lipcius and Hines (1986) showed that a higher abundance of Mya arenaria in sand than in mud in Chesapeake Bay could be explained by differentiated predation rate of Callinectes sapidus determined by the nature of the substrate. Likewise Arnold (1984) and Sponaugle and Lawton (1990) showed that the predation on hard clams by three species of portunid crabs was significantly higher in sand than in shell debris and gravel, indicating that more homogeneous substrata offer less prey protection than heterogeneous substrata. Arnold (1984) and Revelas (1982) estimated that the survival of seeded hard clam and Mytilus, respectively, can be raised by $75 \%$ on complex substrata compared with sandy or muddy bottoms. The increase in survival on complex substrata is partly caused by a prolonged searching time of the predator due to the inherent physical heterogeneity of the substrate (Sponaugle and Lawton 1990). The smell and texture of shell debris may also stimulate the crabs to spend more time handling nonfood items (Sponaugle and Lawton 1990). Furthermore, a preference for being on sand/mud compared to shell debris and gravel may also influence predation rates (Arnold 1984).

\section{Review of the fishery's impact on in- and epifauna}

The use of dredges, beam- and otter trawl and the development of heavier and more powerful fishing gear has increased concern about the impact on benthic communities (see reviews by Jennings and Kaiser 1998; Hall 1999). In Limfjorden observations on commercial dredge tracks and field experiments with controlled dredging have demonstrated a significant short-term effect on the infauna. In particular, the polychaetes associated with mussel beds had a reduced density after dredging, and gastropods and bivalves were also reduced in number after dredging (Dolmer et al. 2002). Shortly after the experimental dredging, the area was invaded by brown shrimps (Crangon crangon) increasing their density from 0.4 to 9.0 individuals $\mathrm{m}^{-2}$. Such an invasion of scavengers feeding on injured or dead animals exposed on the sea bed surface is also reported in other studies (Pranovi and Giovanardi 1994; Thrush et al. 1995). The increased density of brown shrimps accelerates the transport of energy to higher trophic levels, and thereby changes the trophic structure of the ecosystem.

The fishery for mussels also has an impact on the epifauna. A quantitative investigation in 1997 demonstrated that the fishery had no long-term effects on the epifauna composition (Hoffmann and Dolmer 2000). A study in 1999 confirmed this result, but also showed that taxa such as sponges, echinoderms, anthozoans, molluscs, crustaceans and ascideans had a reduced density or were not observed at all 4 months after an area had been fished, indicating that the fishery has a short-term effect on the epifauna (P. Dolmer, unpublished results). In a stressful, eutrophic ecosystem such as Limfjorden, where on average $20 \%$ of the area is exposed to oxygen-depletion annually (data from local authorities), the long-term effects of dredging may be obliterated by the variability caused by other anthropogenic factors, such as eutrophi- 
cation, and natural variability (Jennings and Kaiser 1998). The political objective for the environmental quality plan of the area is to reduce the outlets of nitrogen from the surrounding farmlands by approximately $50 \%$ as defined in the Danish Action Plan for the Aquatic Environment 1 and 2, passed by the Danish Government in 1987 and 1998, respectively. The political threshold value for phosphorus inputs has already been achieved. As the outlets of nitrogen are expected to reach acceptable limits during the next 10 years, thus reducing the impact of eutrophication, then the long-term impacts of mussel dredging will probably become significant and action will need to be taken in order to diminish the effect of the fishery.

\section{Review of the indirect impact at the benthic-pelagic coupling}

Zoobenthic suspension-feeders such as blue mussels dominate in Danish coastal areas. The fishery may affect the population filtration rates and the ability of the mussels to control planktonic biomass by reducing the total filtration capacity as mussels are removed. Their ability to clear large volumes of sea water is important to the transport of energy and materials from the pelagic to the benthic system. Apart from the total filtration capacity of the benthic suspension-feeders, this benthic-pelagic coupling is dependent on mixing processes in the water column and the transport of food particles down to the sea bed (Dolmer 2000a, b). In Limfjorden, records on filtration capacity range from 23 to $180 \mathrm{~m}^{3} \mathrm{~m}^{-2}$ day $^{-1}$ (Riisgård 1991; Dolmer $2000 \mathrm{a}, \mathrm{b}$ ), corresponding to a potential filtration of the whole water column several times a day.

A study by Dolmer (2000b) showed that the number of filtering mussels, and consequently the population filtration rate, was positively correlated to the amount of near-bed chlorophyll. Consequently, the phytoplankton biomass increased in the upper layer of the water column at days with low water-column mixing and filtration activity, and then decreased during days with a mixed water column, as the mussels increased their filtration activity again. Similar patterns have also been observed by Møhlenberg (1995) and Riisgård et al. (1998). Dolmer (2000b) observed that $44-69 \%$ of the mussels in a mussel bed were not filtering at low water-column mixing rates, whereas only $17-25 \%$ of the mussels were passive when the water column was well mixed. Knowledge to the filtration activity pattern under field conditions can be used in an ecosystem management approach: if the fishery removes $25 \%$ of the mussels in the investigated area the remaining mussels should have the capacity to filter at the same rate as before fishing. This may be a very conservative advice for a general exploitation rate, since the mussel density at the investigated station was only $8 \%$ of the densities in other part of Limfjorden (Dolmer 2000b) and a positive correlation may be expected between mussel density and the number of nonpumping individuals.
Today the fishery removes $15 \%$ of the mussel stock each year (Dolmer et al. 1999), which indicates that the fishery may be sustainable in respect of a constant filtration capacity. However, the distribution of the fishery effort has to be evaluated. The present fishery removes almost all mussels on exploited fishing grounds instead of thinning the mussels. Apart from the extensive physical changes, a depletion of mussel stocks in a certain area may eliminate the benthic filtration and thereby lose its capability to control the plankton in that area. A management plan for the mussel fishery may incorporate a spatial distribution of the mussel fishery in order to obtain a sustainable exploitation of the mussel population in respect of a constant filtration capacity and control of plankton biomass.

\section{Towards a more sustainable exploitation}

An ecosystem management plan of the mussel fishery has to handle the trade-off between the impact of the mussel fishery on ecological services and the biological resources of the ecosystem and the socio-economic aspects, including the reduced value of the recreational function of the area, economic aspects as export values and the number of employees (Fig. 4)

A fundamental requirement for a reliable impact analysis of the mussel fishery and for implementing an operational management strategy in an area such as Limfjorden is a basic understanding of the ecological system and its function. The previous sections have highlighted the impact of mussel dredging on the ecosystem and in the following paragraphs we will discuss some modifications and remedial initiatives that can develop the fishery towards a more sustainable practice. Furthermore, we try to identify gaps in the present scientific knowledge necessary to the successful development and implementation of more sustainable practices. A modification of the mussel fishery can be divided into modifications of currently used techniques, new methods and habitat restoration initiatives.

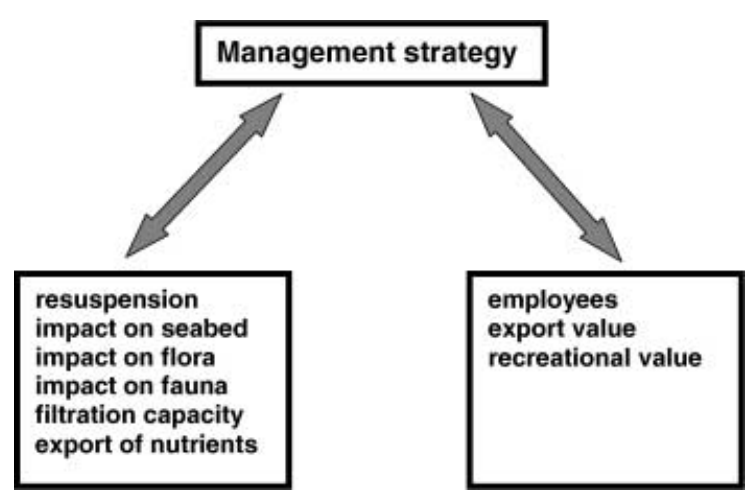

Fig. 4 The management of the mussel fishery is a trade-off between the impact of the fishery on the ecosystem (left side) and socio-economic aspects (right side) 


\section{Modifications of currently used techniques}

The impact of the currently used dredging-techniques for mussels includes degradation of the benthic fauna and physical and chemical changes in seabed structures. Furthermore, the fishery interacts with the transport of nutrients and materials from the pelagic to the benthic system. Initiatives to reduce these effects may be a main target of a management plan. The organisation of the mussel fishery limits the development of the fishery practice on the road towards a more sustainable fishery. At present the fishermen have a license to a vessel and not to an area and cannot plan the harvesting of the mussel stocks in order to optimise the quality of the landings. If they wait too long, the mussels will be landed by their colleagues. This structure of the fishery conflicts with a sustainable fishery practice, where thinning of the mussel beds instead of total exploitation would help to retain a constant benthic filtration and formation of biomass and to produce mussels of a higher quality. As the mussels in Limfjorden are food-limited much of the time (Dolmer 2000a, b), the meat content of landed mussels is often rather low (Fig. 1). A fishery strategy of thinning the mussel beds could improve the quality of the mussels and the value of the mussel landings significantly. At the beginning of the year 2000 the prices for mussels from Limfjorden ranged from $85 \mathrm{ECU} \mathrm{t}^{-1}$ for mussels with $13 \%$ meat to more than $200 \mathrm{ECU} \mathrm{t}^{-1}$ for mussels with more than $20 \%$ meat. So, by optimising the mussel production through thinning of the beds and restricting fishing of mussels to periods with a high quality (e.g. $>20 \%$ meat) and to production areas supporting a high mussel quality, today's earnings could be obtained from a relatively smaller area. In this way, a part of the fishery grounds used at present could be closed, reducing the overall impact of the mussel fishery in the sound. Alternatively, they could be used to increase the output of the mussel production or to other types of mariculture such as long-line cultures of mussels or oyster production. Ecosystem model simulations and large-scale experiments with a thinning fishery have yet to quantify the mussel productions under different fishing scenarios, and may deliver important inputs to a management plan.

The mussel dredge can be modified in order to reduce resuspension and impact on the seabed during fishing. The fishermen's organisation is working on a project whereby they install a smooth gummy-skirt on the rough dredge-underside. The expectations are that the modified dredge will not penetrate the sediment surface as deeply as the normal dredge, and that the modification thereby reduces the resuspension of sediment and the impact on the benthic fauna. Development of fishing gear with a lower impact on the seabed may also be an important topic for future work.

\section{New methods}

The dredging for mussels in Limfjorden has for many years been a low-technology fishery. During recent de- cades the biomass of mussels has been high due to eutrophication, and the fishermen have not been forced to optimise the exploitation of the mussel resources, due to few fishing licenses compared to the mussel biomass and a high income per vessel. Consequently, the fishery has not developed towards a more rational exploitation of the resources.

Transplantation of small mussels is one of the new techniques that is now being tested in Limfjorden. Almost every year Limfjorden is exposed to oxygen depletion resulting in mass mortality of up to $300,000 \mathrm{t}$ of mussels. These events are important to the nutrient cycles and the available fishery resources in the area and the fishery management has to optimise the fishery to counteract these situations. One way to achieve this goal is by transplanting juvenile mussels $(<3 \mathrm{~cm})$ from areas frequently exposed to oxygen depletion to areas with a well oxidised and well mixed water column and hence good growth conditions. The benefits from this technique are multiple. There is an export of nutrients bound in mussel biomass from areas suffering from oxygen depletion to growth areas, where the transplanted mussels will accumulate nutrients from the water body until they are harvested and the nutrients are exported from the ecosystem. Furthermore, through this technique the mussels can be farmed in high densities and other areas can be permanently closed to mussel dredging, conserving the benthic flora and fauna in these areas. In cooperation with the mussel fishery organisation, the Danish Institute for Fisheries Research is performing a large-scale experiment, where 1,000 t of mussels are transplanted from the southern broads of the area to two areas in the central part of the sound in order to test the methods and to find the optimal density of relayed mussels.

In addition, the development of long-line mussel cultures represents an interesting technique that has yet to be tested in Limfjorden. Due to the high primary production, the mussels grow fast and mussels on long-lines are expected to reach about $4.5 \mathrm{~cm}$ in 18 months. An alternative to the long-line system is being tested in Limfjorden. It consists of a float of ten attached, closed PVC tubes, each $48 \mathrm{~m}$ long. A mussel culture is established on nets hanging below each tube. The advantage of this system is that the float is fixed only to one anchor and can drift around this point. The problem with massive accumulation of organic matter on the seabed below the culture is then avoided. An effective harvesting technique still has to be developed before the efficiency of this design can be evaluated.

New methods not only include new practices but also new species. Limfjorden has dense populations of flat oyster, Ostrea edulis, Cerastoderma edulis and Ensis americanus. All three species are economically more valuable than blue mussels and development of fisheries or aquacultures on these species may be interesting alternatives to mussel dredging. 


\section{Habitat restoration initiatives}

The fishery removes seabed materials that are important to the structure and habitat complexity of the sea bed. These structural components include mussels, mussel shells, pebbles and boulders. At present, mussel shells left over from the cooking process of landed mussels and boulders in the landings are classified as waste products and are deposited on land. The amount of shells is approximately $50,000 \mathrm{t}^{\text {year }}{ }^{-1}$ whereas the amount of boulders is unknown but without doubt of importance for the form and function of the ecosystem. Furthermore, mussels below the legal landing size and shell debris from the landings $\left(50,000 \mathrm{t}^{\text {year-1 }}{ }^{-1}\right)$ are relayed in certain plots. The consequence of this practice is an export of important materials from the fishing ground. A more sustainable practice would be a rotation principle, where the structurally important materials are recycled to recently exploited fishing grounds which are then closed for a couple of years. This would speed up the recovery of the ecosystem and enhance the new recruitment of mussels. Alternatively, the shells could be used as a substrate when relaying mussels, thereby increasing the survival of the mussels.

\section{Conclusion}

From the present review of the impact of mussel dredging in Limfjorden it can be concluded that the fishery could be managed in a more sustainable way without reducing the economic outcome of the fishery. A fishery practice where the mussel beds are thinned out when the mussels have reached a high quality, combined with a transplantation practice of mussels from areas with a high mortality to areas with a high growth rate are available tools. Both practices intensify the production in a certain area, leaving other areas open for alternative production or for permanent closure for the benefit of the benthic flora and fauna in the sound. In addition, other shellfish species represent interesting new fishing resources or potential culturing species. Habitat restoration is an important management tool that has to be included in an ecosystem management approach of the mussel fishery.

Acknowledgements Thanks are due to Peter Blanner, Dr Norbert Dankers and an anonymous referee for valuable discussions and suggestions. The study was part of the EU project ESSENSE (Contract FAIR CT98-4201) and was also financially supported by the Ministry of Food, Agriculture and Fisheries (FIFOF-DFU-3 SUSTAINEX).

\section{References}

Arnold WS (1984) The effects of prey size, predator size, and sediment composition on the rate of predation of the blue crab, Callinectes sapidus Rathbun, on the hard clam, Mercenaria mercenaria (Linné). J Exp Mar Biol Ecol 80:207-219

Botero L, Atema J (1982) Behavior and substrate selection during larval settling in the lobster Homarus americanus. J Crust Biol 2:59-69
Bourget E, DeGuise J, Daigle G (1994) Scales of substratum heterogeneity, structural complexity, and the early establishment of a marine epibenthic community. J Exp Mar Biol Ecol 181:31-51

Butman CA, Grassle JP, Webb CM (1988) Substrate choices made by marine larvae settling in still water and in a flume flow. Nature 333:771-773

Butman CA, Fréchette M, Geyer WR, Starczak VR (1994) Flume experiments on food supply to the blue mussel Mytilus edulis $\mathrm{L}$ as a function of boundary-layer flow. Limnol Oceanogr 39:1755-1768

Clausen I, Riisgård HU (1996) Growth, filtration and respiration in the mussel Mytilus edulis: no evidence for physiological regulation of the filter-pump to nutritional needs. Mar Ecol Prog Ser 141:37-45

Dame RF, Prins TC (1998) Bivalve carrying capacity in coastal ecosystems. Aquat Ecol 31: 409-421

Dolmer P (1998) Seasonal and spatial variability in growth of Mytilus edulis L in a brackish sound: comparisons of individual mussel growth and growth of size classes. Fish Res 34: $17-26$

Dolmer P (2000a) Algal concentration profiles above mussel beds. J Sea Res 43:113-119

Dolmer P (2000b) Feeding activity of mussels Mytilus edulis related to near-bed currents and phytoplankton biomass. J Sea Res 44:221-231

Dolmer P, Kristensen PS, Hoffmann E (1999) Dredging of blue mussels (Mytilus edulis L) in a Danish sound: stock sizes and fishery-effects on mussel population dynamic. Fish Res 40:73-80

Dolmer P, Kristensen T, Christiansen ML, Petersen MF, Kristensen PS, Hoffmann E (2002) Short-term impact of blue mussel dredging (Mytilus edulis L) on a benthic community. Hydrobiologia

Dyekjær SM, Jensen JK, Hoffmann E (1995) Mussel dredging and effects on the marine environment. ICES CM 1995/E:13 ref K

Fréchette M, Bourget E (1985) Food-limited growth of Mytilus edulis $\mathrm{L}$ in relation to the benthic boundary layer. Can J Fish Aquat Sci 42:1166-1170

Fréchette M, Butman CA, Geyer WR (1989) The importance of boundary-layer flows in supplying phytoplankton to the benthic suspension feeder, Mytilus edulis L. Limnol Oceanogr $34: 19-36$

Glasby TM (2000) Surface composition and orientation interact to affect subtidal epibiota. J Exp Mar Biol Ecol 248:177-190

Grumbine RE (1994) What is ecosystem management? Conserv Biol 8:27-38

Haamer J, Holm AS, Edebo L, Lindahl O, Norén F, Hernroth B (1999) Strategic mussel cultivation to create recycling and balance in the ecosystem - overview and proposed measures (in Swedish). Fiskeriverket Rapp 6:5-29

Hall SJ (1999) The effects of fishing on marine ecosystems and communities. Blackwell, Oxford

Hedvall O, Moksnes P-O, Pihl L (1998) Active habitat selection by megalopae and juvenile shore crabs Carcinus maenas: a laboratory study in an annular flume. Hydrobiologia 375:89_ 100

Hoffmann E, Dolmer P (2000) Effect of closed areas on the distribution of fish and benthos. ICES J Mar Sci 57:1310-1314

Jacobi CM, Langevin R (1996) Habitat geometry of benthic substrata: effects on arrival and settlement of mobile epifauna. J Exp Mar Biol Ecol 206:39-54

Jennings S, Kaiser MJ (1998) The effects of fishery on marine ecosystems. Adv Mar Biol 34:201-352

Jørgensen BB (1980) Seasonal oxygen depletion in the bottom waters of a Danish fjord and its effect on the benthic community. Oikos 34:34-76

Kaiser MJ, Spencer BE (1996) The effects of beam-trawl disturbance on infaunal communities in different habitats. J Anim Ecol 65:348-358

Lapointe L, Bourget E (1999) Influence of substratum heterogeneity scales and complexity on a temperate epibenthic marine community. J Exp Mar Biol Ecol 189:159-170 
Lee SY, Kneib RT (1994) Effects of biogenic structure on prey consumption by the xanthid crabs Eurytium limosum and Panopeus herbstii in a salt marsh. J Exp Mar Biol Ecol 104:39-47

Lemire M, Bourget E (1996) Substratum heterogeneity and complexity influence micro-habitat selection of Balanus sp and Tubularia crocea larvae. J Exp Mar Biol Ecol 135:77-87

Lenihan HS (1999) Physical-biological coupling on oyster reefs: how habitat structure influences individual performance. Ecol Monogr 69:251-275

Linnane A, Mazzoni D, Mercer JP (2000) A long-term mesocosm study on the settlement and survival of juvenile European lobster Homarus gammarus L in four natural substrata. J Exp Mar Biol Ecol 249:51-64

Lipcius RN, Hines AH (1986) Variable functional responses of a marine predator in dissimilar homogeneous microhabitats. Ecology 67:1361-1371

Møhlenberg F (1995) Regulating mechanisms of phytoplankton growth and biomass in a shallow estuary. Ophelia 42:429-256

Newell RIE, Ott J (2000) Macrobenthic communities and eutrophication. In: Malone TC, Malej A, Harding LW Jr, Smodlaka N, Turner RE (eds) Ecosystems at the land-sea margin: drainage basin to coastal sea. (Coastal and estuarine studies, vol 55) American Geophysical Union, Washington, D.C. pp 265-293

Orth RJ, Heck KL Jr, Montfrans J van (1984) Faunal communities in seagrass beds: a review of the influence of plant structure and prey characteristics on predator-prey relationships. Estuaries 7:339-350

Pilskaln CH, Churchill JH, Mayer LM (1998) Resuspension of sediment by bottom trawling in the gulf of Maine and potential geochemical consequences. Conserv Biol 12:1223-1229
Pranovi F, Giovanardi O (1994) The impact of hydraulic dredging for short-necked clams, Tapes spp. on an infaunal community in the lagoon of Venice. Sci Mar 58:345-353

Revelas EC (1982) The effect of habitat structure on the predator-prey relationship between the green crab, Carcinus maenas, and the blue mussel, Mytilus edulis. Biol Bull 163:367368

Riemann B, Hoffmann E (1991) Ecological consequences of dredging and bottom trawling in the Limfjord, Denmark. Mar Ecol Prog Ser 69:171-178

Riisgård HU (1991) Filtration rate and the growth in the blue mussel Mytilus edulis Linnaeus, 1758: dependence on algal concentration. J Shellfish Res 10:29-35

Riisgård HU, Jensen AS, Jürgensen C (1998) Hydrography, nearbottom currents, and grazing impact of the filter-feeding ascidian Ciona intestinalis in a Danish fjord. Ophelia 49:1-16

Schwinghamer P, Gordon DC, Rowell TW, Prena J, McKeown DL, Sonnichsen G, Guigne JY (1998) Effects of experimental otter trawling on surficial sediment properties of a sandy-bottom ecosystem on the Grand Banks of Newfoundland. Conserv Biol 12:1215-1222

Sponaugle S, Lawton P (1990) Portunid crab predation on juvenile hard clams: effects of substrate type and prey density. Mar Ecol Prog Ser 67:43-53

Thrush SF, Hewitt JE, Cummings VJ, Dayton PK (1995) The impact of habitat disturbance by scallop dredging on marine benthic communities: what can be predicted from results of experiments? Mar Ecol Prog Ser 129:141-150

Wildish DJ, Kristmanson DD (1984) Importance to mussels of the benthic boundary layer. Can J Fish Aquat Sci 41:1618-1625 